\title{
Intestinal malabsorption in cystic fibrosis
}

\author{
D J PENNY, C B INGALl, P BOULTON, J A WALKER-SMITH, AND S M BASHEER \\ Queen Elizabeth Hospital for Children, London, and Department of Paediatrics, Limerick \\ Regional Hospital, Ireland
}

SUMMARY An oral solution containing lactulose and L-rhamnose was administered to six patients with cystic fibrosis. Intestinal absorption of both sugars was assessed by measurement of their urinary excretion. The lactulose: L-rhamnose excretion ratio was raised, supporting the hypothesis of an intestinal component to the malabsorption of cystic fibrosis.

While the role of pancreatic insufficiency in the pathogenesis of the malabsorption syndrome of cystic fibrosis has long been recognised, more recently an intestinal component to the malabsorption has been proposed. ${ }^{1}$

The small intestinal permeability to probe molecules is widely used in the study of small intestinal absorptive function. One such test showed that after oral ingestion of $\mathrm{D}$-xylose patients with cystic fibrosis have higher blood concentrations of D-xylose than controls. $^{2}$ These results were not substantiated, however, by steady state perfusion experiments in isolated in vivo lengths of jejuna. ${ }^{3}$ It was proposed that other mechanisms, such as altered gastrointestinal motility, decreased hepatic metabolism, or decreased renal excretion, might explain the raised blood D-xylose concentrations in cystic fibrosis. ${ }^{3}$

Another test compares the intestinal permeability to the monosaccharide L-rhamnose and the dissaccharide lactulose by simultaneously measuring their urinary excretion after oral ingestion of a solution containing both sugars. ${ }^{4}$ The normal intestine is much less permeable to lactulose than to Lrhamnose, so that the lactulose:L-rhamnose excretion ratio (with both quantities expressed as a percentage of the oral dose ingested) is approximately $0 \cdot 05 .{ }^{4}$ In children the upper limit of normal is considered to be $0 \cdot 07.5$ By studying alterations in the absorption of one substance relative to another, errors due to altered gastrointestinal motility, distribution after absorption, and renal excretion should be minimised. ${ }^{4}$ In this study the lactulose-L-rhamnose test was performed in six patients with cystic fibrosis.

\section{Patients and methods}

Six patients (four boys and two girls) with a mean age of 12 years (range 8-15 years) participated in the study. All had the typical history of cystic fibrosis and raised concentrations of sweat electrolytes at the time of diagnosis. All patients were taking pancreatic enzyme substitutes.

After an overnight fast each patient ingested an oral load $(80 \mathrm{ml})$ containing lactulose $(5.3 \mathrm{~g}$ in $7.5 \mathrm{ml}$ of 'Duphalac' syrup) and rhamnose $(0.75 \mathrm{~g})$. All urine passed over the next five hours was collected, its volume recorded, and a sample, preserved with merthiolate, frozen and stored for analysis.

Urine samples were analysed for lactulose and L-rhamnose by quantitative thin layer chromatography with five upward developments on silica gel layers (Schleicher and Schull F1500), with methanol/ butanol 1-ol/water, 30/30/30, vol/vol as the solvent for the first two developments, butanol 1-ol/ethanol/ acetic acid/water, 60/30/10/10, vol/vol as the solvent for the third and fifth developments, and butanol 1-ol/ethyl acetate/pyridine/acetic acid/water, 5/70/ $15 / 10 / 10, \mathrm{vol} / \mathrm{vol}$ as the solvent for the fourth development, using raffinose and fucose as internal standards. The sugars were measured by dipping in $1.4 \% \mathrm{wt} / \mathrm{vol} 4$ aminobenzoic acid in $3.5 \% \mathrm{vol} / \mathrm{vol}$ orthophosphoric acid in methanol and heating for 10 minutes at $120-130^{\circ} \mathrm{C}$, measuring the resulting colour by densitometry.

Each patient's height $(\mathrm{m})$ and weight $(\mathrm{kg})$ was measured and body mass index (height/weight ${ }^{2}$ ) calculated. Forced vital capacity, forced expiratory volume in one second, and the ratio between these measurements was also measured in each patient. For the purpose of comparison, forced vital capacity was calculated as a percentage of that expected for patient's height. ${ }^{6}$

Standard statistical methods were used in attempting to correlate the lactulose:L-rhamnose excretion ratios with the clinical variables.

\section{Results}

The six subjects excreted $13-111 \mathrm{mg}$ (median value $26.8 \mathrm{mg}$ ) lactulose and $19-89 \mathrm{mg}$ (median value $26.5 \mathrm{mg}$ ) L-rhamnose in the five hours. The lactulose:L-rhamnose ratio was derived from the five hour sugar excretions expressed as a percentage of the oral dose. In these subjects excretion ratios were 
Table Urinary lactulose and L-rhamnose excretion expressed as a percentage of the oral dose ingested and the lactulose:L-rhamnose excretion ratios

\begin{tabular}{llll}
\hline $\begin{array}{l}\text { Case } \\
\text { No }\end{array}$ & $\%$ Recovery & & $\begin{array}{l}\text { Lactulose: } \\
\text { L-rhamnose excretion } \\
\text { ratio }\end{array}$ \\
\cline { 2 - 4 } & Lactulose & L-rhamnose & $0 \cdot 176$ \\
\hline 1 & $2 \cdot 11$ & 11.98 & $0 \cdot 098$ \\
2 & 0.36 & 3.66 & $0 \cdot 23$ \\
3 & 0.57 & $2 \cdot 48$ & $0 \cdot 10$ \\
4 & 0.45 & 4.31 & $0 \cdot 167$ \\
5 & 0.57 & 3.42 & 0.079 \\
6 & 0.26 & 3.28 & \\
\hline
\end{tabular}

$0 \cdot 079-0 \cdot 23$ (median value $0 \cdot 13$ ) (Table). All of these ratios exceed 'normal' values.

There was no significant correlation between the level of the lactulose:L-rhamnose excretion ratio and body mass index $(r=-0.0594)$, forced vital capacity, $(r=-0 \cdot 717)$, or forced expiratory volume in one second: forced vital capacity ratio $(r=-0 \cdot 217)$ in these patients.

\section{Discussion}

This study supports the hypothesis that there is an intestinal component to the malabsorption of cystic fibrosis. The mechanism of this intestinal dysfunction is yet to be elucidated. It seems unlikely that alterations in carrier mediated transport mechanisms are important, as mediated processes contri- bute little to the absorption of lactulose and Lrhamnose. ${ }^{4}$ It has been proposed that the presence of abnormal mucus overlying the intestinal mucosa may alter transport kinetics. ${ }^{3}$

The clinical implications of this intestinal mucosal dysfunction in cystic fibrosis remain to be explored. In this small group of subjects the lactulose:Lrhamnose excretion ratio did not correlate with any of the simple clinical variables selected.

We thank the children and their physicians Dr Watson and Dr McMahon. We thank Ms E Drummond for typing the manuscript.

\section{References}

${ }^{1}$ Morin CL, Roy CC, Lasalle R, Bonin A. Small bowel mucosal dysfunction in patients with cystic fibrosis. $J$ Pediatr 1976;88:213-6.

2 Schaad U, Kraemer R, Gaze H, Hadorn B. One hour blood xylose in cystic fibrosis. Arch Dis Child 1978;53:756-7.

${ }^{3}$ Frase LL, Strickland AD, Kachel GW, Krejs GJ. Enhanced glucose absorption in the jejunum of patients with cystic fibrosis. Gastroenterology 1985;88:478-84.

${ }^{4}$ Menzies IS, Laker MF, Pounder R, et al. Abnormal intestinal permeability to sugars in villous atrophy. Lancet 1979;ii:1107-9.

5 Ford RPK, Menzies IS, Phillips AD, Walker-Smith JA, Turner MW. Intestinal sugar permeability: relationship to diarrhoeal disease and small bowel morphology. Journal of Pediatric Gastroenterology and Nutrition 1985;4:568-74.

${ }^{6}$ Cotes JE. Lung function. 4th ed. London: Blackwell Scientific Publications, 1979.

Correspondence to Dr S M Basheer, Department of Paediatrics, Limerick Regional Hospital, Dooradoyle, Limerick, Ireland.

Received 25 June 1986

\title{
Gastrografin in acute meconium ileus equivalent
}

\author{
S M O'HALLORAN, J GILBERT, O M MCKENDRICK, H M L CARTY, AND D P HEAF \\ Departments of Child Health and Radiology, Alder Hey Children's Hospital, Liverpool
}

SUMmaRY Twenty five $(37 \%)$ patients with cystic fibrosis attending our clinic have experienced acute meconium ileus equivalent. In one year 37 of 40 episodes were treated with single dose oral Gastrografin with an $81 \%$ success rate, $75 \%$ being treated as outpatients. Patients found this treatment preferable to other recommended treatment.

Meconium ileus equivalent is an important complication of cystic fibrosis that reports have suggested occurs in $10-20 \%$ of patients. ${ }^{12}$
Treatment is primarily preventative, using $\mathrm{N}$ acetylcysteine, laxatives, and, in some cases, adjustment of pancreatic enzyme supplements. Surgery during acute attacks carries a high mortality and morbidity from bleeding, poor wound healing, and postoperative chest infections ${ }^{3}$ and should be avoided through effective medical treatment. $\mathrm{N}$ Acetylcysteine given both by nasogastric tube and by enema three times daily ${ }^{3}$ and Gastrografin enemas ${ }^{4}$ have been used successfully but are unpleasant and require admission to hospital. There is little published information about oral Gastrografin in relief of acute meconium ileus equivalent. 